\title{
ENSAIO SOBRE AS IMAGENS DISTORCIDAS DO DOCUMENTÁRIO "NÓS QUE AQUI ESTAMOS, POR VÓS ESPERAMOS"
}

\author{
Regina M. Guarnier Domiciano \\ Docente do Departamento de Letras Clássicas e Vernáculas da \\ Universidade Estadual de Londrina
}

ós que aqui estamos, por vós esperamos, com duração 73 minutos de duração, tem pesquisa, roteiro, direção e produção de Marcelo Masagão. Para produzi-lo, o diretor contou com a seguinte equipe de apoio:

- Efeitos sonoros: André Abujama;

- Consultores de História: José Eduardo Valadares e Nicolau Sevcenko;

- Consultores de Psicanálise: Andréa M. Masagão e Heide Tabacov;

- Consultores Espirituais: Dr. Sigmund Freud e Dr. Eric J. Hobsbawn.

- Responsável pela distribuição: Rio Filmes.

Esse documentário foi lançado em 1999 e ganhou vários prêmios, entre eles, o prêmio de melhor roteiro do II Festival de Cinema Nacional de Recife, melhor documentário no IV Festival Internacional de Documentários "É Tudo Verdade", melhor montagem no XXVII Festival; de Gramado e recebeu a menção honrosa no XVII Festival Internacional de Munique.

A banalização da morte do homem no século XX e a possibilidade de resgate de uma certa dignidade desse morrer no silêncio dos cemitérios constituem o tema desse documentário que é montado a partir de uma seleção de imagens de centenas de outros documentários 
desse século. Com o auxílio de recursos de programas de computador, o diretor interfere, por meio de distorções visuais, em uma das sequiências das imagens de rostos de um grupo de homens que participaram e até mesmo foram mentores de acontecimentos históricos do século XX e essa seqüência será o tema desse ensaio.

Ferreira (1999) registra as seguintes definições para distorção, ampliação e paranóia:

- Distorção:" aberração de um sistema ótico, caracterizada por diferenças de ampliação para diferentes regiões do sistema, e pelo fato de serem deformadas as imagens por ele produzidas."

- Ampliação (óptico): "sistema óptico, cociente entre dimensão linear de uma imagem e a dimensão correspondente do objeto."

- Paranóia: "psicopatia, de que há várias formas clínicas, caracterizada pelo aparecimento de ambições, suspeitas que se acentuam, evoluindo para delírios persecutório e de grandeza estruturados sobre base lógica."

O nariz engole a boca....os olhos são engolidos pelas faces que crescem....incham.....as sobrancelhas tomam conta de um rosto.....humano que rapidamente vai deixando de ser rosto.....vai se tornando des...humano. As imagens desses rostos escorrem, alongam-se, misturam-se, fundindo uma na outra, às vezes se colocam lado a lado, às vezes mais de duas se fundem e finalmente somem. Corta! A imagemcâmera é linguagem, o movimento é linguagem, a cor (branco e preto) é linguagem, o silêncio é linguagem. Essas linguagens se interagem e seus sentidos são reproduzidos na metalinguagem textual. Há nomes que acompanham as sequiências das imagens, e em alguns momentos se ouve palavras, meio confusas, mas a entonação parece ser de ordens a serem cumpridas. As imagens de rostos humanos que se distorcem em branco e preto vão se desfilando e os possíveis sentidos estão lá quando as imagens são mediadas pela memória de arquivos. Essa mediação é necessária por parte daquele que está assistindo o documentário e que procura nos arquivos da memória e outros arquivos, dados que possam identificar tais personagens. $\mathrm{O}$ reconhecimento vai se proces- 
sando conforme a sequiência das imagens vai pedindo a elaboração de uma narrativa que pertence à História: quem?, onde?, por que?, o que?, como?, quando? A recuperação de dados é agilizada porque esses homens foram protagonistas de acontecimentos documentados, reescritos em outros gêneros, filmados, analisados. Em flashes, como no próprio documentário, a memória daquele leu esses textos, assistiu a filmes é uma memória tecida no diálogo entre os múltiplos arquivos que a História registrou.

A tradução das sequiências distorcidas pede um contexto que vão compor múltiplos sentidos, ora mais explícitos, ora mais escondidos na trama do movimento da imagem-câmera. Imagem-câmera que não está mais na câmera, está na sofisticada tecnologia do computador. A sequiência produzida gera uma linguagem visual, mas os possíveis sentidos são resultados da confluência imagem computadorizada e a memória, a convidada necessária. Memória e imagem-câmera dialogam para reiterar a banalização da morte. É a imagem produzida pela distorção que se constituirá no enredo da paranóia que marca a história do século XX.

A primeira tomada é de um rosto em um retrato e de grandes proporções. São vários rostos. Quem são eles?, por que eles e não outros? O close amplia as imagens que adquirem um peso enorme quando os rostos são identificados: Adolph Hitler, Joseph Stalin, Mão Tse-Tung Mussolini, Pen Pot, Franco, Salazar, Idi Amin, Ceausescu, Ferdinand Marcos,Pinochet, Reza Pahalavi, Videla, Médici e Mobutu. A ficha de identificação é montada rapidamente, pois a História Oficial fornece os dados:

Nome: Adolph Hitler';

Nascimento: 1889;

Morte: 1945;

Nacionalidade: austríaco de nascimento;

Profissão: Ditador da Alemanha a partir de 1933;

Responsável pela II Guerra Mundial, pela morte de milhões de judeus e pela devastação da Europa, Ásia e norte da África.

Sobre os dados biográficos de Adolph Hitler, ver Hitler (1973). 
Nome: Joseph V. Stalin ${ }^{2}$

Nascimento: 1879

Morte: 1953

\section{Nacionalidade: russo}

Profissão: Líder do Partido Comunista da União das Repúblicas Socialistas Soviéticas;

Responsável pelo grande expurgo pra implantar a industrialização na Rússia, pela morte de milhares de judeus nos guetos de Varsóvia e eliminação de líderes e prática de traição para chegar ao poder.

A ficha de identificação de Mao Tse-Tung, líder do Partido Comunista Chinês, Mussolini, Ditador da Itália, General Pol Pot no Vietnã, General Franco na Espanha, Salazar em Portugal, Ferdinand Marcos no Equador, General Pinochet no Chile, Reza Pahalavi no Irã, General Videla na Argentina, General Médici no Brasil e Mobutu no Congo não exige da memória que investigue outras rotas. Os nomes não estão completos , pois a memória daquele que assiste não é tão eficiente, basta associar o sobrenome ao fato histórico para instaurar os sentidos necessários.

Os três primeiros dados são "aparentemente" inofensivos e inocentes, como são aparentemente inofensivos e inocentes os "dados" da memória, ratificados pelos arquivos sociais. Mas logo vem um dado sobre Hitler que desequilibra, choca e amedronta:

\section{Responsável pela morte de milhões de judeus nos campos de concentrações entre 1939 a 1945}

Os Frank que iam para escola despreocupados, os Schelligz que faziam jóias para as senhoras, os Flechtheims que cuidavam dos dentes dos Helmuts, os Hessels que trabalhavam na tipografia, os Hirschfelds que pintavam e tinha uma loja de quadros, os Kirdorfs que tinham uma chapelaria, os Lungendorffs que eram professores em Berlim, os Poelzigs, os Roths, os Tollers, os Levins ${ }^{3}$. Primeiro foram proibidos de serem

2 Sobre os dados biográficos de Joseph Stalin, ver Stalin (1973). 
cidadãos, depois sumiram. O silêncio é brutal, mas todos "sabem" o que aconteceu. Com a conivência de "Estávamos cumprindo ordens"; "Os homens que fazem ciência, têm que testar seus métodos", repetidamente pronunciadas por membros da Gestapo no julgamento de Nuremberg +.... (afinal a dor e a humilhação são deles, que pertencem a uma raça inferior.) Esses dados não foram inventados, eles estão lá nos arquivos da Gestapo. Se trocarmos o lugar, eles também estarão na KGB, tão estimada por Joseph Stalin;, estarão nos programas da Revolução Cultural, postos em prática por Mao Tse Tung; nas prisões clandestinas de Salazar e Franco; na caravana da Morte de Pinochet; nas celas de tortura do DOPS. Isso também é História. Nos arquivos da Gestapo estavam os destinos de milhões de judeus:

\subsection{7 ............................. Forno crematório \\ 2.768.790 ............................. Forno crematório \\ 34.987.281 ......................... Forno crematório}

Mas falta muita prova: os corpos dos prisioneiros e dos civis da Espanha, da Itália, de Portugal, da China, do Chile, do Brasil. Como começou essa paranóia, onde está o seu meio e fim? Deve haver alguma linguagem com uma sintaxe que produza sentidos.

As imagens começam a se mover. O programa de computador deve ter um mecanismo sofisticado que, quando acionado, vai criando formas, cuja plasticidade é sedutora pois podem nos levar a imaginar que se trata de um brinquedo: o olho se expande e a boca é engulida; o

\footnotetext{
Já tinha conhecimento, através da leitura de obras que abordam esse tema, sobre o destino dos alemães de origem judia. Cito duas obras que foram consultadas para confirmar dados esparsos da minha memória: Berlim.1919-1933. A encarnação estrema da modernidade. Rio Jameiro: Jorge Zahar, 1993 (Coleção Memória das Cidade) e Ascensão e Queda do $3^{\circ}$. Reich. Rio de Janeiro: Civilização Brasileira. 1967. Vol I

+ Lembranças desses filmes: 'O Julgamento de Nuremberg' com Spencer Tracy, Burt Lancaster e Richard Widmark, dirigido por Stanley Kramer, 1967 e 'Sobreviventes do Holocausto', dirigido por Steven Spielberg de 1996 fazem parte da memória ligada à imagem de Hitler.
} 
nariz se expande, os olhos são engulidos, o bigode aumenta, as sobrancelhas se contorcem. Os rostos se alongam e a fusão é feita por partes das imagens que vão se dissolvendo, e partes que vão nos afrontando e nos enfrentando. É uma dança que nos envolve pois os movimentos possuem leveza e graça e essa dança chega mesmo a ser sedutora. Mas esses movimentos sedutores não podem nos convencer totalmente, é preciso que o distanciamento venha em nosso socorro, por uma certa lucidez. As imagens distorcidas são poderosas. Está tudo documentado: esse ser......humano chamado Adolph Hitler deu ordem para que os judeus poloneses fossem confinados em guetos, cassados nos seus direitos de ir e vir, em condições apropriadas para pegar doenças e morrer....morrer..... inocentemente esse ser....humano deu ordem para construir campos de concentração e depois foi jantar, dançar com Eva Braun.

\section{Responsável pela morte de judeus nos guetos poloneses em e pelo expurgo ideológico de milhares de russos depois da segunda guerra para se manter no poder}

Esse ser...humano chamado Joseph Stalin, para industrializar U.S.S.R. deslocou, na década de 30 mais de 25000000 de agricultores para os centros industriais ${ }^{5}$, transformando-os em trabalhadores pela força e através de um treinamento intensivo; não poupou os bolchevistas nem os líderes militares em 1936, fazendo-os se declararem culpados por meio de traições, terrorismo e espionagem para depois assassiná-los para permanecer no poder. A paranóia vai se instalando no século enquanto outros rostos vão respondendo ao apelo envolvente do poder: Franco, Salazar, Mao Tsé-Tung; Pinochet.......

Os movimento que engolem uma parte do rosto amplia outra, fazem um rosto distorcido que é a metáfora do poder distorcido do ditador que se diz "L'Etait c'est moi" (século XVIII). Ele é o Estado, afinal ele trabalhou duro para chegar lá, e nada melhor do que pensar que ele merece ser o Estado. Leia-se que conveniências (se nega o

\footnotetext{
s Tinha uma vaga memória dos feitos de Stalin. Esses dados foram obtidos em Raymond Carter (1967).
} 
direito de um judeu alemão exercer sua profissão, assim os alemães puros terão mais oportunidades); jogos de interesses. Os trabalhadores alemães podem trabalhar muito mais, eles devem, por amor à pátria preparar a Alemanha para a guerra, mesmo que não tenham sido consultados; cegueira: 'Afinal, do que estou sendo acusado?', perguntam aos intelectuais russos, perguntam os civis chilenos a Joseph Stalin, ao general de Pinochet. Eliminações em massa (nada como uma limpeza étnica diz Hitler, Ceausescu), condescendência, discursos com pedidos de desculpas, silêncio de vozes discordantes tudo isso (isso é uma palavra tão higiênica cujo referente são as vidas humanas) pode muito bem fazer parte de um processo nada inocente que leve a dominação.

E as imagens vão se engolindo, devorando os números, vão tragando os nomes dos chineses, dos espanhóis, dos chilenos, dos brasileiros. A rapidez dessa antropofagia esconde dezenas de anos de guerra, esconde os prisioneiros, esconde centenas de americanos mortos nas areias de Dunquerque ${ }^{6}$, a humilhação nas salas de tortura do DOPS ${ }^{7}$. Esconde também o processo que durou uma década para eliminar “opositores”. Não há nenhuma outra imagem que possa se contrapõe a essas, parece não haver linguagem que faça frente a essas imagens!

Tudo vem a ser demasiado humano: os sentimentos de sedução, de indiferença, de desprezo, de ódio, de possível solidariedade, de amores tão deslocados. Esses sentimentos são tão demasiadamente humanos na medida em que comportam o que o ser humano foi, pode ser, ou virá a ser. Passando pelo portão do cemitério, essas imagens distorcidas desvanecem. Esperam silenciosamente por todos nós que ainda não cruzamos o portão? Não há leituras para o estar em estado de morte, Nós, do lado de cá, somos historicizados pela memória que se constrói na repetição do acontecimento da morte e da sobrevivência que se repete e repete chegando à banalização. A memória de um judeu que sobreviveu de um campo de concentração (1935-45), a memória de um russo que sobreviveu nos campos de trabalhos forçados nas estepes geladas russas (1940-1953), a memória dos que sobreviveram aos mas-

\footnotetext{
'O filme assistido recentemente: 'O resgate do Soldado Ryan', dirigido por Steven Spielberg de 1998.

${ }^{7}$ Lembranças da leitura do livro: Brasil Nunca Mais (1985).
} 
sacres da Praça Tienen (1980-2002) aos massacres para limpeza de étnica, ordenados por Nicolae Ceausescu e Slobodan Milosevic (a grande ausência neste documentário) nas últimas décadas do século $\mathrm{XX}^{8}$ não têm os mesmos sentidos que os meus para essas imagens. Para eles e talvez também para nós, as imagens distorcidas criam a sensação de brinquedo, desfocando a linguagem do morticínio causada por esses seres de imagens distorcidas. Linguagem que tem uma sintaxe sutil. mas inexorável: cassação parcial de direitos (leia-se liberdade de ir e vir, trabalhar) (fase opcional); suspensão de todos os direitos de cidadania, (humilhações de qualquer natureza), (opcional mas aconselhável); envio para campos de refugiados ou campos de concentração, (perda de identidade por tortura, por fome para obter confissões) (fase opcional, mas aconselhável) e, finalmente, morte violenta, individual ou em massa (imprescindível) ${ }^{9}$. De uma certa forma, a linguagem da memória que se sobrepõem às imagens mecânicas dos rostos distorcidos nos alerta para a inocência da nossa expressão de terror e a fragilidade desta metalinguagem diante de uma paranóia tão alastradora e paralisante da banalização da morte nesse século provocada por líderes aparentemente normais.

${ }^{8}$ A memória teima em arquivar, embora de modo incompleto, reportagens da Folha de S. Paulo que divulgou na década de 90 os atos autoritários de Nicolae Ceaucescu e mais recentemente, pelos crimes de limpeza étnica cometidos por Slobodan Milosevic que está sendo julgado pela Corte Internacional de Haia.

"Fazem parte dessas relações, lembranças de filmes assistidos tais como A História Oficial com Hector Alterio e Norma Aleandro, dirigido por Luis Puenzo. lançado em 1985 e Desaparecido, com Jack Lemon e Sissi Spacek de Costa Gravas com roteiro de Costa Gravas e Donald Stewart, lançado em 1982. 


\section{Referências Bibliográficas}

BRASIL Nunca Mais. Petrópolis: Vozes, 1985

CARTER. Raymond. A $2^{\prime}$. Guerra Mundial. Rio de Janeiro: Ed. Larousse do Brasil, 1967.

FERREIRA. Aurélio Buarque de Holanda. Novo Dicionário da Lingua Portuguesa. São Paulo: Nova Fronteira, 1999.

Hitler. GRANDES personagens de todos os tempos. Rio de Janeiro: Ed. Três, 1973. v.5. (Coleção Biblioteca de História)

Sictin. GRANDES Personagens de Todos os Tempos. Rio de Janeiro: Ed. Três, 1973. 1.7 (Coleção Biblioteca de História 